\title{
Meiotic Maturation of Bovine Oocytes Cultured In Vitro with EGF and Wortmannin
}

\author{
Mohamed-Kheir Idris Anas' ${ }^{1}$, Masayuki Shimada² WenXian Zeng ${ }^{2}$ \\ and Takato Terada²* \\ ${ }^{1}$ Graduate School for International Development and Cooperation, Higashi-Hiroshima 739-8528, Japan \\ ${ }^{2}$ Animal Reproduction Laboratory, Applied Biological Science, Hiroshima University, \\ Higashi-Hiroshima 739-8528, Japan
}

\begin{abstract}
This study was designed to examine the effect of EGF on meiotic maturation of bovine oocytes and to evaluate the ability of wortmannin, a specific PI 3-kinase inhibitor, to modulate EGF-induced oocyte maturation. EGF significantly improved meiotic maturation of both cumulus-intact and denuded oocytes. Wortmannin effectively and irreversibly blocked oocytes from progressing to the MIl stage. When oocytes were transferred to wortmannin-treated medium after being cultured for $2 \mathrm{~h}$ in wortmannin-free medium, $36 \%$ of them progressed to the MIl stage. By delaying the time of transfer to $4 \mathrm{~h}, 64 \%$ of the oocytes developed to MII, and by further delaying to $6 h$, the rate of MIl formation was almost similar to that of oocytes cultured without wortmannin supplementation. Culturing of the oocytes with EGF for $2 \mathrm{~h}$ did not improve their meiotic maturation. Increasing the incubation period with EGF for 4 or $6 \mathrm{~h}$ resulted in a maturation rate similar to that of those cultured with EGF for the total period of incubation. Data suggest that EGF is capable of stimulating bovine oocyte meiotic maturation regardless of the presence of cumulus cells, and that PI 3-kinase is involved in this process. Results also show that inhibition of PI 3-kinase from $6 \mathrm{~h}$ after the onset of culture does not block meiotic progression, and that EGF induces its positive maturation signal during the first $4 \mathrm{~h}$ of culture period. Key words: EGF, Wortmannin, Bovine, Oocytes, Meiotic maturation
\end{abstract}

We have recently demonstrated that wortmannin, a specific phosphatidylinositol 3-kinase (PI 3-kinase) inhibitor, prevents bovine oocytes from developing to the MII stage of meiotic maturation without affecting their meiotic resumption [1]. This finding suggests a pos-

Received: June 26, 2000

Accepted: August 29, 2000

*To whom correspondence should be addressed. sible role for $\mathrm{PI} 3$-kinase in regulating the process of meiotic progression. In somatic cells, PI 3-kinase has been reported to be activated by, and implicated in the signaling mechanism of, many growth factors with receptor-associated tyrosine kinase such as NGF, EGF, IGF-I and insulin [2-5]. Several recent studies have shown that growth factors stimulate oocyte maturation in vitro. The positive effect of EGF on meiotic maturation of cattle [6-8], pig [9], mouse [10], rat [11] and rabbit [12] has been demonstrated. However, the biochemical processes that mediate the stimulatory effects of growth factors on oocyte maturation are not yet clearly defined.

The present study was designed to examine the effect of EGF on bovine oocyte meiotic maturation and to see whether EGF-induced meiotic maturation is dependent upon PI 3-kinase activity. The sensitive period during which wortmannin inhibits EGF-mediated meiotic maturation, and the time required for EGF to exert its stimulatory effects were also investigated.

\section{Materials and Methods}

\section{Preparation of oocytes}

Bovine ovaries were collected from a slaughterhouse and transported to the laboratory in saline at $30^{\circ} \mathrm{C}$. Oocytes were recovered by aspiration of 2 to $5 \mathrm{~mm}$ follicles of the ovaries using a 10-ml syringe with an 18$G$ needle. Oocytes with compact unexpanded cumulus cells and with homogeneous ooplasm were selected under a steromicroscope and placed in a watch glass containing Dulbecco's phosphate buffered saline (PBS) supplemented with $0.05 \%(\mathrm{w} / \mathrm{v})$ polyvinyl pyrrolidone (PVP; Sigma, St. Louis, Mo, USA) and $100 \mu \mathrm{g} / \mathrm{ml}$ kanamycin (Sigma). When denuded oocytes (DOs) were used, the recovered cumulus-oocyte complexes (COCs) were vortexed for $1 \mathrm{~min}$ in TCM 199 with Earle's salts 
(Gibco BRL, Grand Island, NY) supplemented with $0.1 \%$ $(w / v)$ hyaluronidase (Sigma), and the remaining cumulus cells were removed mechanically with a small-bore pipette.

\section{Oocytes culture and staining}

Ten to 20 COCs or denuded oocytes were transferred to $100-\mu$ droplets of culture medium in a $35-\mathrm{mm}$ polystyrene culture dish (Falcon plastic, no. 1008, Becton Dickinson and Company, Lincoln park, NJ) covered with mineral oil (Sigma). The basic culture medium (BM) was TCM-199 with Earle's salts supplemented with $0.2 \mathrm{mM} \mathrm{Na-pyruvate} \mathrm{(Sigma),} \mathrm{0.3 \%} \mathrm{PVP} \mathrm{and} 50$ $\mu \mathrm{g} / \mathrm{ml}$ gentamicin (Sigma). All cultures were carried out at $39^{\circ} \mathrm{C}$ in a humidified atmosphere of $5 \% \mathrm{CO}_{2}$ in air. At the end of the incubation period, the COCs were denuded by vortexing for $1 \mathrm{~min}$ in PBS supplemented with $0.1 \%(\mathrm{w} / \mathrm{v})$ hyaluronidase. The denuded oocytes were mounted on slides, fixed for $48 \mathrm{~h}$ in acetic acid and ethanol (1:3), stained with 1\% lacmoid in $45 \%$ acetic acid and examined under a phase-contrast microscope for the stage of meiosis. Oocytes were classified as being at the germinal vesicle (GV), prometaphase I (Pro.MI), metaphase I (MI), anaphase I (AI), telophase (TI) or metaphase II (MII) stages. Degenerated oocytes (with no visible chromatin or with chromatin configuration that could not be recognized at any stage of meiotic division) were excluded from the calculations after the statistical analysis showed no treatment effect.

\section{Preparation of wortmannin}

Wortmannin (Sigma) was initially dissolved in dimethyl sulfoxide (DMSO; Sigma) to $5 \mathrm{mM}$ and kept at $-20^{\circ} \mathrm{C}$. Before use it was diluted again in DMSO and readjusted with the culture medium to a final concentration of $10^{-7} \mathrm{M}$. The final DMSO concentration in the culture medium was $0.098 \%(\mathrm{v} / \mathrm{v})$. A medium with the corresponding volume of DMSO was included and served as control. Due to its instability in aqueous solutions [13] wortmannin-treated medium as well as control medium were changed every $5 \mathrm{~h}$ during the culture period (24 h).

\section{Experimental design}

Experiment 1 was conducted to examine the effect of EGF on meiotic maturation of bovine oocyte, and to see whether wortmannin can modulate EGF-induced oocyte meiotic maturation. Half of the recovered oocytes were denuded, and both denuded and cumulus-intact oocytes were cultured for $24 \mathrm{~h}$ with the following treatments: BM (control), BM+50 ng/ml EGF (E-4127, from mouse submaxillary glands, Sigma, Lot. $065 \mathrm{H} 8821$ ), and $\mathrm{BM}+50 \mathrm{ng} / \mathrm{ml} \mathrm{EGF}+10^{-7} \mathrm{M}$ wortmannin.

In Experiment 2, to assess whether the inhibitory effect of wortmannin on EGF-induced meiotic maturation is reversible, COCs were cultured for $24 \mathrm{~h}$ in the presence of both EGF and wortmannin, then half of the cultured oocytes were examined for their meiotic stage and the remaining oocytes were washed with, and cultured in EGF-supplemented medium for a further $12 \mathrm{~h}$. Some of the oocytes were cultured for $24 \mathrm{~h}$ with EGF and served as a control.

In Experiment 3, to determine the sensitive period in which it is possible to block EGF-mediated meiotic maturation by wortmannin, COCs were cultured with EGF for 2, 4 and $6 \mathrm{~h}$. They were then washed with, and cultured in medium supplemented with EGF and wortmannin for an additional 22, 20 and $18 \mathrm{~h}$, respectively. Some of the COCs were cultured throughout the $24 \mathrm{~h}$ with EGF or with EGF and wortmannin and served as controls.

In Experiment 4, to assess the period required for EGF to induce oocyte meiotic maturation, COCs were cultured in EGF-treated medium for 2, 4 and $6 \mathrm{~h}$. They were then washed with, and cultured in EGF-free medium for an additional 22, 20, and $18 \mathrm{~h}$, respectively. Some of the COCs were cultured for the whole $24 \mathrm{~h}$ in the absence or presence of EGF and served as controls.

\section{Statistical analysis}

Results are presented as the mean percentages \pm SEM. All percentage data were subjected to arc-sine transformation and statistically analyzed by one-way ANOVA. When significance was found in the ANOVA analysis, the treatments were compared by Fisher's protected least significant difference test. A value of $P<0.05$ was considered significant.

\section{Results}

In Experiment 1 (Table 1), when EGF was not added to the maturation medium, the rate of MII formation was significantly higher for COCs than DOs. EGF significantly $(P<0.01)$ increased the proportion of COCs as well as that of DOs which progressed to the MII stage of meiotic maturation. The magnitude of the increase in MII oocytes in response to EGF treatment was almost similar for both COCs and DOs (33.1 vs $28.5 \%$, respectively). For either COCs or DOs, wortmannin did not affect the proportion of oocytes undergoing GVBD and progressing to the Pro.MI, MI stages of maturation. 
Table 1. Meiotic maturation of bovine cumulus-oocyte complexes (COCs) or denuded oocytes (Dos) cultured in vitro with EGF and wortmannin

\begin{tabular}{|c|c|c|c|c|c|c|c|}
\hline & \multirow{2}{*}{$\begin{array}{c}\text { EGF } \\
50 \mathrm{ng} / \mathrm{ml}\end{array}$} & \multirow{2}{*}{$\begin{array}{c}\text { Wortmannin } \\
1 \times 10^{-7} \mathrm{M}\end{array}$} & \multirow{2}{*}{$\begin{array}{l}\text { No. of } \\
\text { oocytes }\end{array}$} & \multicolumn{4}{|c|}{ Percentage of oocytes } \\
\hline & & & & GV & PMI, MI & $\mathrm{AI}, \mathrm{TI}$ & MII \\
\hline \multirow{3}{*}{ COCs } & - & - & 111 & $0.9 \pm 0.9$ & $33.3 \pm 1.9$ a & $1.8 \pm 0.9$ & $64.0 \pm 1.9 \mathrm{a}$ \\
\hline & + & - & 108 & $0.0 \pm 0.0$ & $14.8 \pm 1.9 \mathrm{~b}$ & $0.0 \pm 0.0$ & $85.2 \pm 1.8^{b}$ \\
\hline & + & + & 109 & $3.7 \pm 0.8$ & $79.8 \pm 1.6^{c}$ & $0.9 \pm 0.8$ & $15.6 \pm 1.6^{c}$ \\
\hline \multirow{3}{*}{ DOs } & - & - & 104 & $2.9 \pm 0.3$ & $36.5 \pm 0.6^{a}$ & $7.7 \pm 1.5$ & $52.9 \pm 2.3^{d}$ \\
\hline & + & - & 103 & $2.9 \pm 0.2$ & $22.3 \pm 0.4^{b}$ & $6.8 \pm 1.4$ & $68.0 \pm 1.7 \mathrm{a}$ \\
\hline & + & + & 97 & $6.2 \pm 1.7$ & $76.3 \pm 1.6^{c}$ & $4.1 \pm 1.7$ & $13.4 \pm 2.7^{c}$ \\
\hline
\end{tabular}

$a, b, c, d$ Different superscripts within the same column are significantly different $(p<0.05)$. Values are mean percentages \pm SEM for three replicates.

Table 2. Reversibility of the inhibited effect of wortmannin on EGF-induced meiotic maturation of bovine cumulusoocyte complexes

\begin{tabular}{|c|c|c|c|c|c|c|c|}
\hline \multicolumn{2}{|c|}{ First culture } & \multirow{2}{*}{$\begin{array}{l}\text { Second culture } \\
\text { EGF }(12 \mathrm{~h})\end{array}$} & \multirow{2}{*}{$\begin{array}{l}\text { No. of } \\
\text { oocytes }\end{array}$} & \multicolumn{4}{|c|}{ Percentage of oocytes } \\
\hline EGF (24 h) & Wortmannin (24 h) & & & GV & PMI, MI & $\mathrm{AI}, \mathrm{TI}$ & MII \\
\hline+ & - & - & 71 & $0.0 \pm 0.0$ & $22.5 \pm 1.2 \mathrm{a}$ & $1.4 \pm 1.5$ & $76.1 \pm 0.3 \mathrm{a}$ \\
\hline+ & + & - & 66 & $1.5 \pm 2.3$ & $87.9 \pm 4.5^{b}$ & $1.5 \pm 2.3$ & $9.1 \pm 0.1^{b}$ \\
\hline+ & + & + & 58 & $1.7 \pm 1.9$ & $84.5 \pm 2.6^{b}$ & $0.0 \pm 0.0$ & $13.8 \pm 0.7^{b}$ \\
\hline
\end{tabular}

a,b Different superscripts within the same column are significantly different $(\mathrm{p}<0.05)$. Values are mean percentages \pm SEM for three replicates.

Wortmannin abolished the stimulatory effect of EGF and significantly $(\mathrm{P}<0.05)$ decreased the number of oocytes developing to the MII stage compared to the control for both types of oocytes.

Results of Experiment 2 (Table 2) show that the inhibitory effect of wortmannin was irreversible. The proportion of oocytes cultured for $24 \mathrm{~h}$ with EGF+wortmannin that developed to the MII stage was significantly $(P<0.05)$ lower than those cultured in the absence of wortmannin (9.1 vs $76.1 \%$, respectively). When the oocytes were initially cultured with $\mathrm{EGF}+$ wortmannin for $24 \mathrm{~h}$, then cultured in EGF-treated medium for further $12 \mathrm{~h}$, their MII rate remained similar to that of oocytes cultured with wortmannin for $24 \mathrm{~h}$ (13.8 vs $9.1 \%$, respectively), and was significantly $(\mathrm{P}<0.05)$ lower than that of oocytes cultured without wortmannin (13.8 vs $76.1 \%$, respectively).

In Experiment 3, the sensitive period during which it is possible to inhibit EGF-mediated meiotic maturation was examined. As in Experiment 1, wortmannin, when added from the start of the culture, significantly $(P<0.05)$ decreased the number of oocytes developing to MII stage compared to the control (17.9 vs $79.2 \%$, respectively; Table 3). When the oocytes were cultured with EGF for $2 \mathrm{~h}$ followed by $22 \mathrm{~h}$ incubation with wortmannin, their maturation rate was significantly $(P<0.05)$ higher than that of oocytes cultured with wortmannin from the start of culture (42.5 vs $17.9 \%$, respectively). The maturation rate was further increased $(60 \%)$ when the oocytes were incubated with EGF for $4 \mathrm{~h}$ before transferring COCs to the wortmannin-treated medium. By transferring the oocytes to the wortmannin-treated medium at 6 $\mathrm{h}$ after the onset of the culture, the maturation rate became statistically similar to that of oocytes cultured with EGF for the total period of incubation (76.4 vs $79.2 \%$, respectively).

The result of Experiment 4 is summarized in Table 4. Culturing of the oocytes with EGF for $2 \mathrm{~h}$ followed by $22 \mathrm{~h}$ in EGF-free medium resulted in a maturation rate comparable to that of the oocytes cultured without EGF treatment for the whole period of maturation (69.2 vs $63.5 \%$, respectively). When the oocytes were cultured with EGF for 4 or $6 \mathrm{~h}$ and then transferred to EGF-free medium and cultured up to the end of the maturation period, their maturation rates were statistically similar to that of oocytes cultured with EGF for the whole period of maturation (75.0, 77.1 and $81.0 \%$, respectively). 
106 - J. Mamm. Ova Res. Vol.17, 2000

Table 3. Time-dependent inhibitory effects of wortmannin on EGF-induced meiotic maturation of bovine cumulus-oocyte complexes in vitro

\begin{tabular}{|c|c|c|c|c|c|c|}
\hline $\begin{array}{c}\text { First culture } \\
\text { (hours) }\end{array}$ & $\begin{array}{l}\text { Second culture } \\
\text { (hours) }\end{array}$ & \multirow{2}{*}{$\begin{array}{l}\text { No. of } \\
\text { oocytes }\end{array}$} & \multicolumn{4}{|c|}{ Percentage of oocytes } \\
\hline EGF & EGF + wortmannin & & GV & ProMI, MI & AI, TI & MII \\
\hline 0 & 24 & 106 & $4.7 \pm 0.7$ & $77.4 \pm 1.9 \mathrm{a}$ & $0.0 \pm 0.0$ & $17.9 \pm 1.3 \mathrm{a}$ \\
\hline 2 & 22 & 94 & $4.3 \pm 0.9$ & $48.9 \pm 2.6^{b}$ & $4.3 \pm 1.0$ & $42.5 \pm 2.2 \mathrm{~b}$ \\
\hline 4 & 20 & 115 & $5.2 \pm 0.1$ & $34.8 \pm 1.0^{c}$ & $0.0 \pm 0.0$ & $60.0 \pm 1.1^{c}$ \\
\hline 6 & 18 & 106 & $1.9 \pm 1.2$ & $19.8 \pm 2.9 \mathrm{~d}$ & $1.9 \pm 0.9$ & $76.4 \pm 3.9 \mathrm{~d}$ \\
\hline 24 & 0 & 101 & $2.0 \pm 1.1$ & $16.8 \pm 1.0 \mathrm{~d}$ & $2.0 \pm 1.5$ & $79.2 \pm 0.8^{d}$ \\
\hline
\end{tabular}

$a, b, c, d$ Different superscripts within the same column are significantly different $(p<0.05)$. Values are mean percentages \pm SEM for three replicates.

Table 4. Effect of culturing bovine cumulus-oocyte complexes with EGF for specific periods on their meiotic maturation in vitro

\begin{tabular}{|c|c|c|c|c|c|c|}
\hline $\begin{array}{c}\text { First culture } \\
\text { (hours) }\end{array}$ & $\begin{array}{l}\text { Second culture } \\
\text { (hours) }\end{array}$ & \multirow{2}{*}{$\begin{array}{l}\text { No. of } \\
\text { oocytes }\end{array}$} & \multicolumn{4}{|c|}{ Percentage of oocytes } \\
\hline EGF & Without EGF & & GV & ProMI, MI & AI, TI & MII \\
\hline 0 & 24 & 115 & $0.0 \pm 0.0$ & $35.6 \pm 2.6^{a}$ & $0.9 \pm 0.6$ & $63.5 \pm 2.2^{a}$ \\
\hline 2 & 22 & 94 & $0.0 \pm 0.0$ & $28.7 \pm 1.8 \mathrm{ab}$ & $2.1 \pm 1.0$ & $69.2 \pm 1.2 \mathrm{ab}$ \\
\hline 4 & 20 & 128 & $0.8 \pm 0.5$ & $21.1 \pm 0.9 b c$ & $3.1 \pm 1.5$ & $75.0 \pm 0.8 \mathrm{bc}$ \\
\hline 6 & 18 & 96 & $0.0 \pm 0.0$ & $22.9 \pm 0.5 \mathrm{bc}$ & $0.0 \pm 0.0$ & $77.1 \pm 0.4^{c}$ \\
\hline 24 & 0 & 100 & $1.0 \pm 1.3$ & $17.0 \pm 0.7 c$ & $1.0 \pm 1.2$ & $81.0 \pm 0.8^{c}$ \\
\hline
\end{tabular}

$a, b, c$ Different superscripts within the same column are significantly different $(p<0.05)$. Values are mean percentages \pm SEM for three replicates.

\section{Discussion}

Although the stimulatory effect of EGF on maturation of cumulus-enclosed oocytes has been reported in various species [6, 7, 9-12, 14-16], many of these reports have failed to find any positive effect for EGF on the denuded oocytes, suggesting that EGF acts through the cumulus cells $[7,12,14-16]$. The results of this study show that EGF can stimulate bovine oocyte meiotic maturation irrespective of the presence or absence of cumulus cells. The magnitude of the increase in the proportion of oocytes developing to the MII stage as a result of EGF treatment was similar for both cumulus-intact and denuded oocytes, suggesting that EGF does not totally depend on cumulus cells to exert its stimulatory effects. In agreement with this finding, Das et al. [17] and more recently Lonergan et al. [6] have reported direct evidence of a maturation-promoting effect for EGF on murine, human and bovine denuded oocytes. The use of only denuded oocytes that were derived from the healthy collected cumulus-intact oocytes rather than those found denuded at the time of aspiration might be the reason behind the contradiction in the results of the present study to those of other investigators who have been able to demonstrate the stimulatory effect of EGF only in the present of cumulus cells. Lonergan et al. [6] also suggested that oocytes found to be nude on aspiration are probably inherently less competent. Moreover, we have recently compared the effect of EGF on meiotic maturation of both types of denuded oocytes and found that whereas EGF promoted maturation of denuded oocytes derived from the collected COCs, it had no effect on those found denuded at the time of aspiration [18]. Thus it is likely that the positive effect of EGF is dependent upon the source of oocytes rather than the presence of cumulus cells. This assumption is supported by the fact that the presence of EGF receptors in bovine and porcine oocytes has been reported [6, 19], and that the stimulatory effect of EGF on meiotic maturation of mouse oocytes was shown to be independent of cumulus expansion [10].

Our results also show that in the absence of EGF, the proportion of oocytes developing to the MII stage of maturation was significantly higher for cumulus-intact oocytes than denuded oocytes, and it was assumed 
that the surrounding cumulus cells are beneficial for oocytes during meiotic maturation as reported by many other investigators [20-23]. With EGF treatment, the proportion of denuded oocytes developing to the MII stage was similar to that of COCs cultured without EGF supplementation. Therefore, it appears likely that the difference in the maturation rate between the two types of oocytes was due to the action of endogenous EGF secreted by the cumulus cells. This is further supported by the findings of Singh et al. [19] who provided an evidence that EGF is synthesized by the cumulus cells.

EGF is a polypeptide growth factor that exerts its biological effects by binding to a membrane receptor. Binding of EGF to its receptor will lead to the activation of the receptor-associated tyrosine kinase, a first step in the signal transduction pathway [24]. The stimulatory effect of EGF on bovine oocyte meiotic maturation was blocked by erbstatin, a specific tyrosine kinase inhibitor $[18,25]$, indicating that this growth factor acts through a tyrosine kinase pathway to stimulate oocyte maturation. However, the biochemical process following the activation of EGF receptor-associated tyrosine kinase and the second messenger systems which mediate its stimulatory effect on oocyte meiotic maturation is not well understood. Tyrosine kinase activation following EGF binding to its receptor initiates phosphorylation of several cellular proteins that act as tyrosine kinase substrates. These include PI 3-kinase, Ras, MAP kinase and raf kinase [24]. We have recently demonstrated that inhibition of PI 3-kinase prevented bovine oocytes from developing beyond the MI stage of maturation, suggesting a possible role for this enzyme on MI to MII meiotic progression [1]. Based on these observations, and the fact that the activation of $\mathrm{PI} 3$ kinase by EGF and many other growth factors with receptor-associated tyrosine kinase, it is assumed that $\mathrm{PI}$ 3-kinase is one of the components of the signal transduction pathway of EGF-induced meiotic maturation. To verify this speculation, the effect of wortmannin, a specific PI 3-kinase inhibitor, on EGF-induced meiotic maturation was examined.

Our results showed that incubation of the oocytes with wortmannin and EGF resulted in a significant decrease in the percentage of oocytes developing to the MII stage, indicating that PI 3-kinase activity is needed for EGF-mediated oocyte maturation. Since wortmannin also blocked the action of EGF on denuded oocytes, we speculate that cumulus cells do not mediate the inhibitory effect of wortmannin, and thus PI 3-kinase in the oocyte itself might mediate the effect of EGF. The results also showed that the inhibitory effect of wortmannin was irreversible. This irreversibility is consistent with the finding of Yano et al. [26] who reported that wortmannin inhibited PI 3-kinase activity through an irreversible binding to a 110 catalytic subunit of the enzyme.

We then examined the sensitive period during which it is possible to inhibit EGF-induced meiotic maturation with wortmannin. The results showed that whereas the presence of wortmannin from the start of the culture significantly inhibited the oocytes from developing to MII, it had no effect when added $6 \mathrm{~h}$ after the start of culture, suggesting that at this time PI 3-kinase has already been activated. These results indicate that although PI 3-kinase seems to be activated earlier during meiotic maturation, its activity is linked with the transition from MI to MII rather than the earlier stages of maturation. Thus it is reasonable to assume that activation of PI 3-kinase is followed by a cascade (s) of other kinase (s) which regulate the meiotic progression beyond MI.

On the basis of this finding, if EGF induces meiotic maturation through this PI 3-kinase pathway, then we speculate that this growth factor induces its stimulatory signal at an early stage of meiotic progression. To test this hypothesis we examined the period required for EGF to stimulate the meiotic maturation. The results revealed that culturing of oocytes with EGF for 4 to $6 \mathrm{~h}$ is sufficient to promote their maturation to a rate similar to that of those cultured with this growth factor throughout the total period of maturation. This evidence suggests that EGF generates its positive signal necessary to complete oocyte meiotic maturation at an early stage of the maturation period. This finding, the result of the inhibitory effect of wortmannin, and the existence of EGF receptors on the oocytes [6, 19], led us to conclude that EGF stimulates oocyte maturation through a receptor-mediated signal transduction pathway of which PI 3-kinase is likely to be involved.

In conclusion, it was demonstrated that EGF does not depend totally on the cumulus cells to exert its stimulatory effect on oocyte meiotic maturation, that PI 3-kinase activity is needed for EGF-induced oocyte maturation, and that EGF generates its stimulatory signal at an early stage of nuclear maturation.

\section{Acknowledgments}

The authors thank the staff of the meat inspection office in Hiroshima for supplying bovine ovaries. 


\section{References}

1) Anas, M-K, I., Shimada, M. and Terada, T. (1998): Possible role for phosphatidylinositol 3-kinase in regulating meiotic maturation of bovine oocytes in vitro. Theriogenology, 50, 347-356.

2) Cantley, L.C., Auger, K.R., Carpenter, C., Duckworth, B., Graziani, A., Kapeller, R. and Soltoff, S. (1991): Oncogenes and signal transduction. Cell, 64, 281-302.

3) Carter, A.N. and Downes, C.P. (1992): Phosphatidylinositol 3-kinase is activated by nerve growth factor and epidermal growth factor in PC 12 cells. J . Biol. Chem., 267, 14563-14567.

4) Kotani, K., Yonezawa, K., Hara, K., Yeda, H., Kitamura, Y., Sakaue, H., Ando, A., Chavanieu, A., Calas, B., Grigorescu, F., Nishiyama, M., Waterfield, M.D. and Kasuga, M. (1994): I nvolvement of phosphoinositide 3-kinase in insulin- or IGF-I-induced membrane ruffling. EMBO J ., 13, 2313-2321.

5) Ruderman, N.B., Kapeller, R., White, M.F. and Cantley, L.C. (1990): Activation of phosphatidylinositol 3-kinase by insulin. Proc. Natl. Acad. Sci. USA, 87, 1411-1415.

6) Lonergan, P., Carolan, C., Langendonckt, A.V., Donnay, I., Khatir, H. and Mermillad, P. (1996): The role of epidermal growth factor in bovine oocyte maturation and preimplantation embryo development in vitro. Biol. Reprod., 54, 1420-1429.

7) Lorenzo, P.L., Ilera, M.J ., Illera, J.C. and Illera, M. (1994): Enhancement of cumulus expansion and nuclear maturation during bovine oocyte maturation in vitro by the addition of epidermal growth factor and insulin-like growth factor-I. J. Reprod. Fertil., 101, 697-701.

8) Park, Y.S. and Lin, Y.C. (1993): Effect of epidermal growth factor and defined simple media on in vitro bovine oocyte maturation and early embryonic development. Theriogenology, 39, 475-484.

9) Ding, J . and Foxcroft, G.R. (1994): E pidermal growth factor enhances oocyte maturation in pig. Mol. Reprod. Dev., 39, 30-40.

10) Downs, S.M. (1989): Specificity of epidermal growth factor action on maturation of the murine oocyte and cumulus oophorus in vitro. Biol. Reprod., 41, 371379.

11) Dekel, N. and Scherizly, I. (1985): Epidermal growth factor induces maturation of rat follicle-enclosed oocytes. Endocrinol ogy, 116, 512-516.

12) Lorenzo, P.L., Rebollar, P.G., Illera, M.J ., Illera, J .C., Illera, M. and Alvarino, J.M.R. (1996): Stimulatory effect of insulin-like growth factor-I and epidermal growth factor on the maturation of rabbit oocytes in vitro. J . Reprod. Fertil., 107, 109-117.

13) Kimura, K., Hattoris, S., Kabuyama, Y., Shizawa, Y., Takayanagi, J ., Nakamura, S., Toki, S., Matsuda, Y., Onodera, K. and Fukui, Y. (1994): Neurite outgrowth of PC12 cells is suppressed by wortmannin, a specific inhibitor of phosphatidylinositol 3-kinase. J. Biol. Chem., 269, 18961-18967.

14) Coskum, S. and Lin, Y.C. (1993): Site of action of epidermal growth factor (EGF) on in vitro porcine oocyte maturation. Endocrine J . 1, 87-91.

15) Downs, S.M., Daniel, S.A.J . and Eppig, J J. . (1988): Induction of maturation in cumulus cell-enclosed mouse oocytes by follicle-stimulating hormone and epidermal growth factor: evidence for a positive stimuIus of somatic cell origin. J . Exp. Zool., 245, 86-96.

16) Lorenzo, P., Illera, M.J., Sanchez, J ., Silvan, G. and Illera, J.C. (1992): The effect of EGF on cumulus expansion and bovine oocyte maturation in vitro. Theriogenology, 37, 1.

17) Das, K., Tagatz, C.E., Stout, L.E., Phipps, W.R., Hensleigh, H.C. and Leung, B.S. (1991): Direct positive effect of epidermal growth factor on the cytoplasmic maturation of mouse and human oocytes. Fertil. Steril., 55, 1000-1004.

18) Anas, M-K, I., Elmileik, A., Maeda, T. and Terada, T. (1998): Effects of epidermal growth factor, insulin like growth factor-I and insulin on meiotic maturation of bovine denuded oocytes. J . Mamm. Ova Res., 15, 179184.

19) Singh, B., Rutledge, J .M. and Armstrong, D.T. (1995): Epidermal growth factor and its receptor gene expression and peptide localization in porcine ovarian follicles. Mol. Reprod. Dev., 40, 391-399.

20) Fukui, Y. and Sakuma, Y. (1980): Maturation of bovine oocytes cultured in vitro: Relation tom ovarian activity, follicular size and presence or absence of cumulus cells. Biol. Reprod., 22, 669-673.

21) Leibfried-Rutledge, M.L., Critser, E.S., Parrish, J .J . and First, N.L. (1989): In vitro maturation and fertilization of bovine oocytes. Theriogenology, 31, 61-74.

22) Shioya, Y., Kuwayama, M., Fukushima, M. and I wasaki, S. (1988): In vitro fertilization and cleavage capability of bovine follicular oocytes classified by cumulus cells and matured in vitro. Theriogenology, 30, 489-494.

23) Zhang, L., J iang, S., Wozniak, P.J., Yang, X. and Godke, R.A. (1995): Cumulus cell function during bovine oocyte maturation, fertilization, and embryo development in vitro. Mol. Reprod. Dev., 40, 338-344.

24) Carpenter, G. and Cohen, S. (1990): E pidermal growth factor. J . Biol. Chem., 265, 7709-7712.

25) Izadyar, F., Colenbrander, B. and Bevers, M.M. (1997): Stimulatory effect of growth hormone on in vitro maturation of bovine oocytes is exerted through the cyclic adenosine $3^{\prime}, 5^{\prime}$-monophosphate signaling pathway. Biol. Reprod., 57, 1484-1489.

26) Yano, H., Nakanishi, S., Kimura, K., Hanai, N., Saitoh, Y., Fukui, Y., Nonomura, Y. and Matsuda, Y. (1993): Inhibition of histamine secretion by wortmannin through the blockade of phosphatidylinositol 3-kinase in RBL-2H3 cells. J . Biol. Chem., 268, 25846-25856. 